\title{
Sexual Mimicry in Hyenas
}

\section{Citation}

Muller, Martin N, and Richard Wrangham. 2002. "Sexual Mimicry In Hyenas." The Quarterly Review of Biology 77 (1): 3-16. https://doi.org/10.1086/339199.

\section{Permanent link}

http://nrs.harvard.edu/urn-3:HUL.InstRepos:41467428

\section{Terms of Use}

This article was downloaded from Harvard University's DASH repository, and is made available under the terms and conditions applicable to Other Posted Material, as set forth at http:// nrs.harvard.edu/urn-3:HUL.InstRepos:dash.current.terms-of-use\#LAA

\section{Share Your Story}

The Harvard community has made this article openly available.

Please share how this access benefits you. Submit a story.

Accessibility 


\title{
The Quarterly Review of Biology

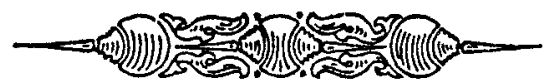

\section{SEXUAL MIMICRY IN HYENAS}

\author{
Martin N. Muller \\ Department of Anthropology, Peabody Museum, Harvard University \\ Cambridge, Massachusetts 02138 USA \\ E-MAIL: MULLER@FAS.HARVARD.EDU \\ RICHARD WRANGHAM \\ Department of Anthropology, Peabody Museum, Harvard University \\ Cambridge, Massachusetts 02138 USA \\ E-MAIL: WRANGHAM@FAS.HARVARD.EDU \\ KEYWORDS \\ sexual mimicry, spotted hyenas, androgenization, genital masculinization, \\ monomorphism, siblicide, infanticide, natural selection, adaptation
}

\section{ABSTRACT}

Genital masculinization in female spotted hyenas has been widely explained as an incidental consequence of high androgen levels. High androgen levels, in turn, were supposed to be favored because they led to adaptive aggressive behavior. Incidental androgenization is no longer a tenable hypothesis, however, because genital masculinization has been shown to proceed in the absence of androgenic steroids. Thus, an alternative hypothesis is required. The genitals of spotted hyena females are not simply masculinized, but exhibit a detailed physical resemblance to the male genitalia. In the absence of satisfactory alternative explanations, we propose that selection may have favored sexual mimicry in females because they are more likely than males to be targets of aggression from other females. Malelike camouflage could theoretically be protective in three contexts: neonate sibling aggression, infanticide by conspecific females, and interclan territoriality. Current data suggest that if sexual mimicry is important, its effects are strongest among infants.

The Quarterly Review of Biology, March 2002, Vol. 77, No. 1

Copyright (C) 2002 by The University of Chicago. All rights reserved.

0033-5770/2002/7701-0001\$15.00 
F EMALE SPOTTED HYENAS (Crocuta crocuta) present an unsolved puzzle because they exhibit one of the most extraordinary genital morphologies of any mammal. In this review we show that as a result of recent experiments, the principal previous explanation for their male-like genitals is no longer viable. This leads us to suggest a new explanation, that female mimicry of males serves to protect females from lethal aggression by same-sex rivals.

\section{Sexual Monomorphism in Spotted Hyenas}

Male spotted hyenas have a long and sometimes prominent penis. Female spotted hyenas have a clitoris of similar size, shape, and erectile ability. They have no external vagina. Instead, females urinate, mate, and give birth through the urogenital canal, which extends through the length of the clitoris. In addition to the pseudopenis, females have a pseudoscrotum created by fusion of the external labia. Fat and connective tissue inside the pseudoscrotum bear a striking resemblance to the male hyena's testes, but are distinguishable from these by palpation (Matthews 1939; Deane 1962; Wickler 1969; Kruuk 1972; Frank 1996). This suite of characteristics makes females so male-like that close examination of the shape of the urethral meatus, the phallic glans, or the scrotum is often required to differentiate the sexes (Frank et al. 1990). It is particularly difficult for field observers to discriminate infants, juveniles, and subadults (Kruuk 1972; Frank 1996).

Spotted hyena females exhibit a second unusual trait that has been argued to relate to genital masculinization: they are more aggressive than males (Frank 1996). Hyena clans maintain linear dominance hierarchies in which adult females are dominant to adult males in nearly all social interactions (Kruuk 1972; Tilson and Hamilton 1984; Frank 1986; Henschel and Skinner 1987; Smale et al. 1993). They regularly displace males from kills, so effectively that Frank (1996) has observed a single subadult female prevent as many as five adult males from feeding on a carcass. Female dominance over males occurs even though the two sexes are similar in size. Specifically, their linear dimensions are indis- tinguishable, though females are heavier (Mills 1990; Glickman et al. 1993).

\section{The Nonadaptive Hypothesis}

Although a number of adaptive hypotheses have been proposed to account for the malelike genitalia of spotted hyena females, none has proved convincing (see below). Instead, the predominant explanation is that malelike genitals are a nonfunctional consequence of androgenization. This hypothesis was prompted by Racey and Skinner's report that serum testosterone levels in female spotted hyenas are as high as those in males (Racey and Skinner 1979). Racey and Skinner also found that females in two other species of hyena (striped hyenas, Hyaena hyaena, and brown hyena, Hyaena brunnea) do not develop masculinized genitalia, are not systematically dominant to males (Mills 1990; Owens and Owens 1996), and have much lower testosterone levels than males. They therefore suggested that high androgen levels in spotted hyena females might be responsible for both their dominance and their masculinized genitalia.

Gould and Vrba (1982) extended Racey and Skinner's proposal to argue explicitly that the enlarged clitoris of female hyenas is nonadaptive (see also Gould 1981). They noted that in the standard course of mammalian sexual differentiation, female external genitalia develop in both sexes in the absence of androgens. Androgens produced by the fetal testes are necessary for the normal development of a penis and scrotum from the undifferentiated genital tubercle and genital folds (Wilson et al. 1981). In humans, rare disorders such as congenital adrenal hyperplasia, which produce excess androgens in the fetal circulation, can cause enlarged clitorises and false scrotums in females (Breedlove 1992). Similar structures, including pseudopenises with erectile function, are exhibited by female dogs exposed to high levels of androgens in utero (Beach et al. 1983). In many mammals, exposure to androgens during critical periods of development also leads to increased body weight and enhanced aggression (Monaghan and Glickman 1992). Thus, Gould (1981) argued that if selection had favored high levels of circulating androgens in female 
hyenas for reasons related to dominance, an enlarged clitoris and pseudoscrotum would be "automatically produced." This explanation has been widely accepted. For example, "the female phallus may have originated as an unselected side effect of selection for androgen-mediated bellicosity, a major advantage in the extraordinary competitive hyaena social system" (Frank 1997:58).

Though rooted in the supposed selective advantages of high androgen levels and female aggressiveness, this hypothesis views female genital masculinization as an incidental by-product. Critical features of this "nonadaptive hypothesis" are that there should be high benefits to female dominance, and few costs associated with masculinized genitalia.

A strong selective advantage for female dominance in spotted hyenas is indeed clear (Frank 1996, 1997; Holekamp et al. 1996). Unlike striped and brown hyenas, which tend to forage solitarily (Owens and Owens 1978), spotted hyenas regularly feed in groups (Kruuk 1972; Hofer and East 1993a). As many as 30 individuals can converge on a freshlykilled ungulate. Therefore competition for food, both scramble (favoring rapid consumption) and contest (favoring social dominance), is often intense (Kruuk 1972; Tilson and Hamilton 1984; Frank 1997). Frank (1997) notes that "within minutes" a group of hyenas can reduce a $220 \mathrm{~kg}$ wildebeest to "bloody stains on the grass."

High-ranking females and their offspring dominate access to carcasses (Tilson and Hamilton 1984; Frank 1986). They therefore have markedly higher reproductive success than subordinates, by maintaining shorter interbirth intervals and having more surviving offspring (Holekamp et al. 1996). They also begin breeding at younger ages (Holekamp et al. 1996). Whereas subordinate females exhibit better reproductive performance during periods of prey abundance than during periods of prey scarcity, dominant females show no such variance (Holekamp et al. 1996). The consequence of these inequalities is that high-ranking females enjoy an estimated 2.5 to 2.75 times greater lifetime reproductive success than low-ranking females (Frank 1996). This result lends crucial support to the idea that selection would favor high levels of circulating androgens in female hyenas if they increased body size and aggressiveness, even at the expense of masculinized genitalia.

\section{Collapse of the Nonadaptive HYPOTHESIS}

Further work on spotted hyena endocrinology in the wild and in a captive colony at the University of California (Berkeley) initially supported the nonadaptive hypothesis. Frank et al. (1985) measured circulating testosterone levels in a large sample of wild hyenas and, in contrast to Racey and Skinner (1979), detected significant differences between the sexes. Testosterone levels were found to be substantially higher in males than females, conforming to the general mammalian pattern. Levels of androstenedione, however, proved higher in females than in males, the opposite of what occurs in most mammals (Lindeque and Skinner 1982; Glickman et al. 1987; van Jaarsveld and Skinner 1991; Glickman et al. 1993). This excess androstenedione in females appears to originate from the ovaries (Glickman et al. 1993). Androstenedione is an inactive "prohormone" which can be converted to either estrogen or testosterone, depending on the presence of the enzymes aromatase and $17 \beta$-hydroxysteroid dehydrogenase (Milgrom 1990). Experiments by Yalcinkaya et al. (1993) showed that, due to low aromatase activity and relatively large concentrations of $17 \beta$-hydroxysteroid dehydrogenase, the spotted hyena placenta is extremely efficient at converting androstenedione to testosterone. Consequently, because placental testosterone is transported to the developing fetus via the umbilical vein, spotted hyena fetuses of both sexes are exposed to relatively high levels of testosterone in utero (Licht et al. 1992; Licht et al. 1998). These experiments made the nonadaptive hypothesis more compelling by offering clear evidence of a hormonal mechanism that could be expected to masculinize both behavior and genitalia.

Subsequent studies have revealed problems with the nonadaptive hypothesis, however. First, the costs of genital masculinization have been found to be high. Whereas most mammalian birth canals are straight, the spotted 
hyena's curves sharply, extending through the clitoris to a length of approximately $60 \mathrm{~cm}$ (Frank et al. 1995b). Because the umbilical cord is only $12-18 \mathrm{~cm}$ long, newborn hyenas often separate from the placenta, get caught in the end of the birth canal, and die from anoxia (Frank and Glickman 1994). In captivity, mortality of firstborns due to dystocia is approximately 60\% (Frank et al. 1995b). Birth complications also contribute significantly to mortality among primiparous females. It is possible that problems with parturition are exacerbated in captivity where, compared to the wild, hyenas are relatively sedentary and overweight (Holekamp, personal communication). However, Frank et al. (1995b) estimate that in the wild, more than $8 \%$ of females die giving birth to their first offspring. In total, it appears that spotted hyena females lose between 16 and $25 \%$ of their expected lifetime reproduction because of their odd reproductive anatomy (Glickman et al. 1993; Frank et al. 1995b; Frank 1996, 1997).

These high costs imply that if genital masculinization is a nonfunctional consequence of other effects, the system of genital differentiation must be constrained in extraordinarily tight ways. For in the absence of some clear benefit, the high costs mean that there should be strong selection pressure to mitigate the effects of prenatal testosterone exposure on female reproductive tissue. Yet mammalian sexual differentiation is notable for its plasticity. It is a complicated cascade of events that can be disrupted at numerous stages to produce a variety of intermediate organs (Breedlove 1992). And while circulating androgens do play an important role in the process, they do not act indiscriminately. Rather, a variety of mechanisms has evolved to regulate their effects. Some tissues are more sensitive to androgens than others because they contain higher concentrations of androgen receptors. Others are less sensitive because they contain lower concentrations of the enzymes necessary to convert inactive prohormones (like androstenedione) to their active forms. If the masculinized genitalia of female hyenas have no adaptive value, then it seems reasonable to ask why selection has not acted to make the clitoris less sensitive to androgens by, for example, reducing the number of androgen receptors or reducing the concentration of enzymes that convert testosterone to dihydrotestosterone? It is difficult to argue that the requisite variation is not present, as receptor densities in target tissues, for example, vary within and between individuals, both pathologically and physiologically (Milgrom 1990).

Cognizant of these issues, Glickman et al. (1993) noted that the effects of prenatal testosterone exposure on sexual organization are indeed partly mitigated in female spotted hyenas. For instance, androgen exposure during spotted hyena development does not cause a reduction in maternal behavior, disruption of fertility, or defeminization of sexual behavior, all of which are routine effects in other mammals. Glickman et al. concluded that in hyenas, "the distribution of steroid receptors (or metabolizing enzymes) in target tissues of the nervous system might allow for selectivity of action, sparing sexual organization while promoting size and aggressiveness" (1993:101).

If the normal masculinizing effects of androgens can be avoided in the brain and in the ovaries, then why not in the external genitalia? This puzzle led researchers from the spotted hyena project in Berkeley to conduct a series of experiments that examined in detail the effects of testosterone on sexual differentiation (Drea et al. 1998; Glickman et al. 1998; Licht et al. 1998). Remarkably, spotted hyenas proved to deviate substantially from the standard mammalian pattern of sexual differentiation. In particular, genital masculinization in this species appears to be largely independent of androgens.

In most mammals, genital masculinization is driven by testosterone produced by the fetal testes after they have developed from the indifferent gonads. The development of the testes themselves is driven by the testis determination factor (TDF) gene, carried on the $\mathrm{Y}$ chromosome (Wilson et al. 1981). Licht et al. (1998), however, found that in spotted hyenas the external genitalia of both males and females were masculinized by day 33 of gestation, before gonadal differentiation had occurred. The implication is that if androgens are responsible for the basic process of geni- 
tal masculinization, they must be coming from the placenta rather than the fetus.

To test this idea, Drea et al. (1998) treated eight pregnant spotted hyenas with a combination of antiandrogens and examined the effects on their infants. In most mammals such treatments result in female external genitalia in both female and male offspring. This general effect was found in hyenas, as males exposed to antiandrogens were born with female-typical genitalia; that is, their penises exhibited the "large urogenital meatus" and "glans with a rounded contour" characteristic of hyena clitorises. Surprisingly, however, the lack of prenatal androgens did not affect the basic structure of the external genitalia in either sex. Females continued to exhibit peniform clitorises and fused labia. Drea et al. concluded that while androgens do produce subtle differences in the genital morphologies of male and female hyenas, they are not responsible for the basic process of clitoral enlargement and labial fusion. They suggested that "there is an androgen-independent mechanism in spotted hyenas that promotes the development of clitoral-penile tissues and the fusion of the genital swellings to form a scrotum, or pseudoscrotum" (1998:126). They note that in a similar way, a nonandrogenic mechanism is responsible for sexual differentiation in some marsupials, which form either a female pouch or a scrotum from abdominal tissue in an independent, genetically controlled process (Renfree and Short 1988). Additional evidence that androgens are not involved in the process of spotted hyena clitoral enlargement was reported by Frank (1997), who noted that at Berkeley, "[e]fforts to demonstrate androgen binding by androgen receptors in fibroblasts cultured from penile and clitoral tissues have been unsuccessful" (1997:61).

The hypothesis of nonandrogenic female genital differentiation was further tested by Glickman et al. (1998), who examined the effects of juvenile gonadectomy. In the standard course of mammalian development, high concentrations of circulating androgens during puberty are associated with accelerated penile growth. Thus, juvenile gonadectomy ordinarily has the effect of reducing penile growth. Glickman et al. (1998) showed experimentally, however, that a lack of androgens during adolescence has little effect on genital morphology in spotted hyenas. This makes sense, as the majority of growth in both the penis and the clitoris is achieved before the pubertal increase in circulating androgens. Glickman et al. summarize the recent findings of the Berkeley group: "The overall results suggest that the initial formation of the fetal phallus, and its subsequent growth during fetal and postnatal life, can proceed in a remarkably 'normal' (for a spotted hyaena) fashion without the influence of gonadal androgens" (1998:134).

Thus, the hypothesis that female genitalia in spotted hyenas are masculinized by circulating androgens has been falsified by the experimental data. Accordingly, the nonadaptive hypothesis-the pseudopenis and associated structures are maintained as an incidental byproduct of high androgen levels-must be wrong.

Recently Goymann et al. (2001) employed noninvasive methods to monitor androgen levels in a large sample of Serengeti spotted hyenas. Their findings cast doubt upon a second element of the nonadaptive hypothesis; namely, that increased levels of circulating androgens are responsible for female dominance and hyperaggressiveness in this species. Goymann et al. found that male hyenas had significantly higher $\mathrm{T}$ and DHT levels than females. Furthermore, they found no difference in androstenedione levels between females and postdispersal males; predispersal males showed significantly lower levels than both of these classes. Goymann et al. argue that earlier studies showing significantly increased levels of androstenedione in female hyenas (Glickman et al. 1987, 1993; van Jaarsveld and Skinner 1991) are problematic because they either did not specify which class of males was sampled or were performed with captive animals, which may not accurately reflect the endocrine status of animals in the wild. Additionally, they note that male and female infants are exposed to the same hormonal milieu in utero. Thus, if prenatal androgen exposure is responsible for female hyperaggressiveness, the mechanism of androgenization must differ between males and females. Goymann et al. conclude that andro- 
gens are not likely to be involved in the hyperaggressiveness of female hyenas. Whether or not their study is corroborated by future research, it seems clear that androgens are not essential for genital masculinization in this species.

\section{Previous Adaptive Hypotheses}

Rejection of the nonadaptive hypothesis emphasizes the significance of the high costs of genital masculinization in female spotted hyenas, and reinforces the interest in finding compensatory benefits. Unfortunately, however, the hyena literature contains few alternatives to the Gould and Vrba hypothesis (Frank 1996, 1997). Kruuk (1972) argued that the enlarged clitoris evolved as an important element in the hyena "meeting ceremony." When two hyenas come together after an absence, or following an aggressive interaction, they often inspect each other's erect genitals closely, sniffing or licking them for ten to thirty seconds. Kruuk suggested that the erect genitalia function to reduce tension by diverting attention from an animal's canines. They also facilitate social bonds by "keeping partners together over a longer meeting period." This, says Kruuk, "could be the selective advantage that has caused the evolution of the females' and cubs' genital structure." Kruuk's explanation seems unlikely, however, given the major reproductive costs associated with a masculinized reproductive anatomy, and the fact that the clitoris is not an indispensable part of the meeting ceremony. Frank (1996) notes that other hyena species engage in similar greeting behaviors, but they focus their attention on the anal glands rather than the genitalia.

East et al. (1993) also note the importance of the erect "penis" in meeting ceremonies, but posit an additional advantage to the fused labia exhibited by female spotted hyenas. They argue that this feature prevents male hyenas from forcing copulation with females, giving females control over mating. However, Frank (1996, 1997) convincingly dismisses this hypothesis by noting that no attempts at forced copulation have been observed in any species of hyena, and that forced copulation is rare among mammals generally. Addition- ally, he points out that female hyenas are so dominant to males that they do not need such an unwieldy mechanism to dissuade "overly ardent males."

All other major hypotheses offered to explain the peniform clitoris of spotted hyena females have relied upon the assumption that the organ is a side effect of androgen exposure (reviewed in Frank 1997). Accordingly, none of the hypotheses reviewed to date appear capable of accounting for masculinized genitals in female spotted hyenas.

\section{Sexual Monomorphism as Sexual Mimicry: The Camouflage Hypothesis}

Genital masculinization in female spotted hyenas is so complete that the sexes are indistinguishable when young. Sexual monomorphism is rare in mammals, but in other taxa it is sometimes known to be related to the scrambling of recognition cues. Sexual cue-scrambling has been studied principally in the context of male mimicry of females, such as female-like male lizards remaining small to avoid aggression from dominant males (Trivers 1976), giant cuttlefish impersonating females to divert male attention while sneaking copulations (Norman et al. 1999), or red-sided garter snakes exuding female-like skin lipids to distract rival males from females (Shine et al. 2000). Female mimicry of males, by contrast, is relatively rare, but has been hypothesized to explain sexual monomorphism in certain ungulates, where male-like females may benefit by avoiding unwanted courtship (e.g., wildebeest: Geist 1974). In a similar way, certain morphs of the female damselfly (Ischnura ramburi) look and behave like males, allowing them to avoid unwelcome mating attempts that can result in increased risk of predation and drowning (Robertson 1985; Sirot and Brockmann 2001).

Sexual monomorphism is also widespread in birds, though it is less clear whether mimicry is responsible, and if so, who mimics whom (Trail 1990; Amundsen 2000). But mimicry is possible, given that in several monomorphic birds, individuals cannot easily distinguish the sex of conspecifics (Burley 1981; Langmore and Bennett 1999). Male birds 
that look like females may benefit by avoiding aggression from more dominant males (Rohwer et al. 1980), or by gaining a competitive advantage over other males through surprise attack (Saetre and Slagsvold 1996).

In a similar way, we suggest that sexual monomorphism in spotted hyenas could be adaptive mimicry. Female spotted hyenas sometimes attack and/or kill female rivals. Females that possess more male-like genitals could thereby gain some protection by appearing male and, thus, be less worth attacking or killing (Wrangham and Peterson 1996).

In theory there are at least three contexts in which the camouflage hypothesis could apply: siblicide by same-aged infants, infanticide by adults, and adult-killing by extragroup rivals. In practice, however, the physical resemblance of females to males declines from infancy onwards. Thus, during the first two to three months of life, female and male cubs cannot be distinguished by humans. But by the time they are juveniles, subtle differences have emerged in the shape of the glans (Frank et al. 1990). Among adult hyenas, body shape, pitch of the "whoop" vocalization, and behavior all allow experienced human observers to identify the sex (Holekamp, personal communication). Parous females, in particular, are easily distinguished by their pulled nipples and torn clitorises (Kruuk 1972). If sexual mimicry is adaptive, its greatest significance should therefore be in infancy. Because hyenas rely heavily upon senses other than sight, sexual mimicry should extend to other sensory modalities, including (theoretically) smell, taste, touch, and sound. This possibility is discussed in further detail below.

\section{Camouflage as a Defense Against SIBLICIDE}

In favor of sexual mimicry as a defense against siblicide, intense aggression has been reported among newborns (Frank et al. 1991; Golla et al. 1999). Infants are born into a den in a small cavity where the mother cannot easily reach them. In addition to having open eyes, functional incisors, and strikingly muscular necks and jaws, infants have prema- turely large canines. In captivity they are quick to attack and shake any moving objects that they can bite. This suggests that attacking and killing their siblings constitute adaptive tendencies.

Females may be particularly vulnerable because female philopatry and strongly biased breeding success with high rank intensifies rivalry among females (e.g., Silk 1983). Studies in both Masai Mara (Frank et al. 1991) and Serengeti (Hofer and East 1997) support the idea that female infants are the most frequent targets of siblicide. In Serengeti, for example, infant spotted hyenas emerging from their dens exhibit unbalanced sex ratios (Hofer and East 1997; James and Hofer 1999). Female singletons there are more common than male singletons, and male twins are more common than female twins, implying that females are more likely than males to kill their same-sex twins (Hofer and East 1997).

Specifically, Hofer and East (1997) reported that by three months of age, infant hyenas in their study included 39 male and 52 female singletons. MM, MF, and FF twin pairs numbered 29, 69, and 16 respectively. Although lethal aggression was not directly observed, Hofer and East noted that the observed sex ratio could be produced in only three ways: (1) a bias in the sex ratio at birth, (2) sex-specific postnatal mortality other than siblicide, or (3) sex-biased siblicide. They rejected the first two hypotheses as being inconsistent with the difference between the sex ratios for twins and singletons, and concluded that siblicide must be more common in female-female pairs (see Table 1).

Frank and colleagues (1991) employed a different definition of siblicide in Masai Mara from that of Hofer and East (1997). In the former study, the sex ratio of twins was observed two to six weeks after birth; in the latter, sex ratios were observed at three months (see also James and Hofer 1999). In Masai Mara, as in the Serengeti, mixed-sex litters were more common than would be predicted by chance, and among same-sex litters, male-male pairs were more common than female-female pairs. Based on the assumption that litters typically contain two infants, the rate of siblicide has been estimated 
TABLE 1

Probabilities of spotted hyena siblicide in the Serengeti

\begin{tabular}{llc}
\hline & \multicolumn{2}{c}{ Sex of the Killer } \\
\cline { 2 - 3 } Sex of the Victim & Male & Female \\
\hline Male & 0.25 & 0.18 \\
Female & 0.18 & 0.44 \\
\hline
\end{tabular}

Probabilities of siblicide in male/male, male/female, and female/female twins from Serengeti (James and Hofer 1999, calculated from the data in Hofer and East 1997). The probabilities are based upon an observed sample (at three months of age) of 39 male and 52 female singletons, and MM, MF, and $\mathrm{FF}$ twin pairs numbering 29, 69, and 16. The model assumes that all litters start out as twins, and that the primary sex ratio is 0.5 . Both of these assumptions have been challenged (Smale et al. 1999).

between $9.6 \%$ (Serengeti, Tanzania: Hofer and East 1997) and ca. 25\% (Mara, Kenya: Frank et al. 1991).

If female newborns indeed attack and kill their sisters more than their brothers, selection could favor females that resemble males, and (as a counterstrategy) female ability to detect the sex of their sibling. In theory, these opposing trends could generate a high degree of sexual mimicry in all relevant modes, i.e., visual (including behavioral), auditory, tactile, taste, and smell. This predicts that infant spotted hyenas should be less skilled at detecting other infants' sex (by smell, licking, or sound, for example) than are infant brown or striped hyenas. The significance of high levels of circulating androgens in fetal and newborn females could therefore include conferring a male-like smell, both in utero and after birth.

We are unaware of any explanation for the exaggeration of penile size in infants. However, if selection favors aggression targeted towards females (by either siblings or adult conspecifics), it may be beneficial for males to exaggerate their maleness (thereby reducing the risk of being mistaken for a female). Large penile size during infancy might therefore be the consequence of selection for males to avoid resembling females. If so, the strategy has been successfully countered by enlargement of the female clitoris. Behavioral convergence is seen in the ability of infant females to erect their clitoris.
Against this hypothesis, infant spotted hyenas appear so aggressive in captivity-even biting a towel-that it may not matter what the victim looks or smells like. Additionally, Smale et al. (1999) have recently argued that siblicide is less common than Frank et al. (1991) or Hofer and East (1997) suggest. They note that evidence concerning siblicide in the wild is largely indirect, inferred from the number and sex of infants that emerge from dens. They suggest that fighting among neonates indeed occurs, but is directed more towards establishing dominance than eliminating rivals. Since surviving losers are permanently subordinate, there is no need to kill them. Smale et al. (1999) interpret the high frequency of singletons emerging from dens as a result of lone births, rather than of litters reduced by siblicide; they suggest that the low numbers of same-sex twins reported by Frank et al. (1991) and Hofer and East (1997) may be a result of birth sex ratios that deviate from unity.

Thus, the importance of siblicide as a source of mortality remains uncertain. Direct observation of infants from birth to emergence from the den are required to assess its frequency and to test whether, for example, better male mimics are more likely to escape intense domination by their sisters. A portable ultrasound machine is currently being used in the field to compare litter sizes before birth with those that emerge from the den two to four weeks after birth (Holekamp, personal communication). These data will eventually produce one test of the siblicide hypothesis.

\section{Camouflage as a Defense Against INFANTICIDE}

Sexual mimicry could also be a defense against infanticide. Adult females are known to commit infanticide in captivity (Frank et al. 1995a), and in the wild they exhibit a "tendency" to kill the neonates of lowerranking females (Frank 1996, 1997). This phenomenon has also been documented by Hofer and East (1995), who state that the most important sources of juvenile mortality in Serengeti are "observed and presumed infanticide by adult clan members ... and ob- 
served and presumed siblicide" (1995:344). Indirect evidence for infanticide includes "the reluctance of small cubs to exit the burrow in the presence of adults, and the care they seem to show in ascertaining the identity of their mother before exiting" (Frank et al. 1995a:379).

Unfortunately there are currently no published data on the frequency of infanticide in hyena clans, nor on the sex distribution of its victims (Frank, personal communication). This is not surprising, as infanticide is difficult to observe in the wild, and hyena neonates cannot conveniently be sexed by field researchers until they are two to three months old (James and East 1999). Additionally, it is sometimes difficult for fieldworkers to distinguish between hyena cubs killed by lions and those killed by conspecifics (Frank et al. 1995a). A few cases of infanticide (unpublished) have been directly observed in the long-term study sites, but these are not yet sufficient to indicate the significance of infanticide for spotted hyena mortality; "it could be great, or it could be trivial" (Holekamp, personal communication).

However, the pattern of local resource competition and male dispersal in spotted hyenas is consistent with the prediction that high-ranking females should selectively target female offspring for infanticide (Silk 1983). In primates this pattern is evident in a range of cercopithecines, where high-ranking females selectively harass lower-ranking individuals carrying female fetuses or immature females (Silk 1983). If female cubs are at particular risk for intragroup infanticide, they may benefit by appearing to be male. Frank et al. (1995a) state that "[s] everal incidents of infanticide in captive hyenas confirm that females of the same social group may be a lethal threat to cubs under 3 months of age" (1995a:379). As mentioned previously, this is the age at which fieldworkers can distinguish the sexes with some reliability.

Although additional field observations are needed to assess the significance of infanticide among spotted hyenas, tests of the hypothesis could be conducted in captivity. The prediction is that adult hyenas should be better at detecting the sex of juveniles (or infants older than three months) than they are at de- tecting the sex of neonates. Additionally, other species of hyena should be better than spotted hyenas at detecting the sex of neonates. If these predictions are incorrect, then the hypothesis is falsified.

A final prediction of both the siblicide and infanticide hypotheses, one that has been tested, is that the degree of mimicry should be greatest in neonates during the period of highest risk, from both infanticide and siblicide. Golla et al. (1999) reported that the mean age of cubs classified as probable siblicides in their study was 59.2 days plus or minus 24. And Frank et al. (1995a) note that the risk of infanticide is greatest for infants less than three months old. As previously noted, humans can only begin to distinguish the sex of infant hyenas at three months.

\section{Camouflage as a Defense Against INTERGROUP AGgRESSION}

Aggression is also intense in between-clan interactions. According to Goodall (1986), a patrolling group consists of at least three high-ranking females. "[A] patrol almost always gives chase if it encounters a lone hyena, or a pair, even if these neighbors are in their own territory. A captured individual may be mauled and left to die" (1986:527). Although systematic data have not been published, incidents of death from interclan aggression have been described from Tanzania by Goodall and van Lawick (1970) and Kruuk (1972), from South Africa by Henschel and Skinner (1991), and in Botswana by Joubert and Joubert (1992). Intolerance of strangers is so great that after females leave the clan temporarily and forage alone during lean times, they may be attacked by their own clan on their return. Males who leave the clan and return, however, do not experience such aggression (Holekamp et al. 1993).

As indirect evidence for intergroup aggression, hyena females in all study sites defend territories by scent marking, vocalizing, making regular boundary patrols, and responding aggressively to intruders (Goodall and van Lawick 1970; Kruuk 1972; Henschel and Skinner 1991; Hofer and East 1995). Henschel and Skinner (1991) reported that spotted hyenas in Kruger National Park spent 
$20 \%$ of their total activity period and distance on territorial patrol, mostly along borders with the clans that intruded most frequently. Additionally, in playback studies in both the Kalahari (Mills 1990) and the Timbavati Game Reserve (Bearder 1984), hyenas either answered or did not react to the calls of other clan members, but moved aggressively towards the speaker when the calls of nonclan members were played.

The fission-fusion nature of spotted hyena social organization would seem to make hyenas particularly vulnerable to lethal aggression by neighbors. In the Serengeti, Hofer and East (1993a,b,c) have described a "commuter system" in which members of a clan must often leave their territory when the migratory species that they feed upon are not locally abundant. During these periods, hyenas fission into small groups of 1-8 individuals and go on "commuting trips." Territory holders react aggressively to invaders when they encounter them. In such encounters territory holders also generally have the advantage of numbers. During 52 recorded encounters, residents outnumbered commuters in $83 \%$, and equaled them in $17 \%$. A vast majority of commuters in Hofer and East's study were solitary. By appearing to be male from a distance, solitary individuals might decrease the probability of pursuit and attack by resident females.

In our scenario, the benefits to females of mimicking males in interclan interactions derive from two features of spotted hyenas. First, females and males have the same body dimensions (Glickman et al. 1993). Similar body size makes close mimicry possible, unlike lions (Panthera leo) for example. Second, spotted hyenas have female philopatry. This means that females are likely to be more determined defenders of a clan range than males (since females have no options of moving to a new clan, unlike males). It also means that a clan's coalitionary power is reduced more predictably by eliminating a female than a male, since females are recruited only by maturation, whereas males can be recruited from other clans. For both these reasons, therefore, if territorial competition is intense, it should benefit clans to attempt to kill neighboring females. Accordingly, females who more closely resemble males might be selected less often as the target of interclan attacks by neighbors. Against this hypothesis, interclan killings do not necessarily occur at high rates. Thus they have not been recorded in Frank's long-term study in Mara, Kenya (Frank 1996), nor in the Kalahari (South Africa) where spotted hyena densities are low (Mills 1990).

An additional problem with applying the mimicry hypothesis to adult hyenas is that the physical similarities between the sexes clearly diminish with increasing age. Thus, human observers can readily distinguish adult males from adult females by the pitch of the "whoop" vocalization, body shape, and social behavior. Parous females are particularly easy to distinguish, due to distinctive changes in their nipples and clitorises. Since hyenas are known to distinguish individuals on the basis of their vocalizations (Holekamp et al. 1999), they can also be expected to distinguish between the sexes. Hyenas can also probably determine the sex of other adults by smell (Holekamp, personal communication). A final complication for the theory is that, among adults, the clitoris is often retracted into the abdomen, where it cannot be observed by conspecifics (Frank and Glickman, personal communication).

Thus, under most circumstances the benefits of sexual mimicry appear unlikely to be important for adults. Theoretically, mimicry might be possible for nulliparous females encountering strangers at a distance, where scent cues are unavailable. In the commuting system described above, females traveling in border areas or through strange territories frequently encounter groups of hostile residents with whom they are not familiar (Hofer and East 1993b). The hypothesis would require that in such situations nulliparous females refrain from vocalizing, maintain their distance, and adopt a male-like submissive posture (including an erect clitoris), in order to maximize the likelihood of successful mimicry. In fact, Hofer and East (1993b) report that nonresident hyenas commonly exhibit such behaviors upon encountering territory holders. It is not clear, however, whether residents are actually confused about the identity of intruders during territorial encounters. 
Thus, in spite of this possibility, the theoretical benefits of sexual mimicry appear to be much more important for infants than adults.

\section{Conclusion}

For at least two decades the large and masculinized genitals of female spotted hyenas have been regarded as a nonadaptive consequence of selection for high androgen levels. The nonadaptive hypothesis was never robustly tested, however, because no explanations were sought for why females were androgenized in some traits (e.g., clitoral morphology) but not in others (e.g., reproductive physiology). A series of experiments on the development of spotted hyena infants has now shown that contrary to expectation, female spotted hyena genitals develop their typical masculine form even in the absence of androgenic steroids. This falsifies the nonadaptive hypothesis for maintenance of genital masculinization. It remains possible, nevertheless, that genital masculinization began as an incidental consequence of high androgen levels in females, providing the chance opportunity for selection to act.

Certainly the fact that genital masculinization is now largely independent of androgenic action, together with the evidence that masculinization causes high costs to females, suggests that the size, shape, and musculature of female spotted hyena genitals have subsequently been subject to positive selection to resemble those of males. Adaptive hypotheses are therefore required. We propose that masculinization of female spotted hyena genitals represents the endpoint of an arms race for female mimicry of males, favored by a tendency for females to direct more intense aggression towards females than to males. Field and captive observations can provide tests of the following predictions:
1. Female cubs should be more at risk from aggression than male cubs.

2. Aggressors should have difficulty distinguishing the sex of their potential victims (whether through sight, smell, taste, touch, or sound).

3. Sexual mimicry (in all relevant sensory modalities) should be greatest during the period of highest risk.

4. Other species of hyena should discriminate between infant females and males better than spotted hyenas.

If any of these predictions is shown to be incorrect, then the mimicry hypothesis is falsified.

Gould (1981) criticized adaptationism as naive on the basis that "organic material is not putty, and natural selection is not omnipotent." Natural selection can indeed be constrained in important ways (reviewed in Dawkins 1982). However, by reducing the byproduct explanation of spotted hyena genital masculinization to the status of a Just-So Story, the data from wild and captive hyenas illustrate that the naivveté of previous hypotheses lay not in their relationship to natural selection, but in asserting their validity without a strong empirical test. Whether or not the camouflage hypothesis is ultimately falsified, the hyena case suggests that there is no a priori reason for favoring nonadaptive over adaptive hypotheses.

\section{ACKNOWLEDGMENTS}

We thank David Haig and Kern Reeve for discussions, and Richard Estes, David Haig, and Craig Stanford for comments. We also thank Laurence Frank, Stephen Glickman, Kay Holekamp, and an anonymous reviewer for extended commentaries on the manuscript.

\section{REFERENCES}

Amundsen T. 2000. Why are female birds ornamented? Trends in Ecology Eै Evolution 15:149-155.

Beach F A, Buehler M G, Dunbar I F. 1983. Sexual cycles in female dogs treated with androgen during development. Behavioral and Neural Biology 38:1-31

Bearder S K. 1984. How hyenas communicate. Page
156 in The Encyclopedia of Mammals, edited by D Macdonald. New York: Facts on File.

Breedlove S M. 1992. Sexual differentiation of the brain and behavior. Pages 39-70 in Behavioral Endocrinology, edited by J B Becker et al. Cambridge (MA): MIT Press.

Burley N. 1980. The evolution of sexual indistinguish- 
ability. Pages 121-137 in Natural Selection and Social Behavior, edited by R D Alexander and D W Tinkle. New York: Chiron Press.

Dawkins R. 1982. The Extended Phenotype. Oxford: Oxford University Press.

Deane N N. 1962. The spotted hyaena Crocuta crocuta crocuta. The Lammergeyer 2:26-44.

Drea C M, Weldele M L, Forger N G, Coscia E M, Frank L G, Licht P, Glickman S E. 1998. Androgens and masculinization in the spotted hyaena (Crocuta crocuta). 2. Effects of prenatal anti-androgens. Journal of Reproduction and Fertility 113:117-127.

East M L, Hofer H, Wickler W. 1993. The erect 'penis' is a flag of submission in a female-dominated society: greetings in Serengeti spotted hyenas. Behavioral Ecology and Sociobiology 33:355-370.

Frank L G. 1986. Social organisation of the spotted hyaena (Crocuta crocuta). II. Dominance and reproduction. Animal Behaviour 34:1510-1527.

Frank L G. 1996. Female masculinization in the spotted hyena: endocrinology, behavioral ecology, and evolution. Pages 78-131 in Carnivore Behavior, Ecology, and Evolution, edited by J L Gittleman. Ithaca (NY): Cornell University Press.

Frank L G. 1997. Evolution of genital masculinization: why do female hyaenas have such a large 'penis'? Trends in Ecology Eं Evolution 12:58-62.

Frank L G, Davidson J M, Smith E R. 1985. Androgen levels in the spotted hyaena Crocuta crocuta: the influence of social factors. Journal of Zoology 206:525531.

Frank L G, Glickman S E. 1994. Giving birth through a penile clitoris: parturition and dystocia in the spotted hyena (Crocuta crocuta). Journal of Zoology 234:659-690.

Frank L G, Glickman S E, Licht P. 1991. Fatal sibling aggression, precocial development, and androgens in neonatal spotted hyenas. Science 252:702-704.

Frank L G, Glickman S E, Powch I. 1990. Sexual dimorphism in the spotted hyena (Crocuta crocuta). Journal of Zoology 221:308-313.

Frank L G, Holekamp K E, Smale L. 1995a. Dominance, demography, and reproductive success of female spotted hyenas. Pages 364-384 in Serengeti II: Dynamics, Management, and Conservation of an Ecosystem, edited by A R E Sinclair and P Arcese. Chicago: University of Chicago Press.

Frank L G, Weldele M L, Glickman S E. 1995b. Masculinization costs in hyenas. Nature 377:584-585.

Geist V. 1974. On the relationship of social evolution and ecology in ungulates. American Zoologist 14:205220.

Glickman S E, Coscia E M, Frank L G, Licht P, Weldele M L, Drea C M. 1998. Androgens and masculinization of genitalia in the spotted hyaena (Crocuta crocuta). 3. Effects of juvenile gonadectomy. Journal of Reproduction and Fertility 113:129-135.
Glickman S E, Frank L G, Davidson J M, Smith E R, Siiteri P K. 1987. Androstenedione may organize or activate sex reversed traits in female spotted hyenas. Proceedings of the National Academy of Sciences 84:3444-3447.

Glickman S E, Frank L G, Holekamp K E, Smale L, Licht P. 1993. Costs and benefits of "androgenization" in the female spotted hyena: the natural selection of physiological mechanisms. Pages 87-117 in Perspectives in Ethology, edited by P P G Bateson. New York: Plenum Press.

Golla W, Hofer H, East M L. 1999. Within-litter sibling aggression in spotted hyaenas: effect of maternal nursing, sex and age. Animal Behaviour 58:715-726.

Goodall J. 1986. The Chimpanzees of Gombe: Patterns of Behavior. Cambridge (MA): Harvard University Press.

Goodall J, van Lawick H. 1970. Innocent Killers. Boston: Houghton Mifflin.

Gould S J. 1981. Hyena myths and realities. Natural History 90:16.

Gould S J, Vrba E S. 1982. Exaptation-a missing term in the science of form. Paleobiology 8:4-15.

Goymann W, East M L, Hofer H. 2001. Androgens and the role of female "hyperaggressiveness" in spotted hyenas (Crocuta crocuta). Hormones and Behavior 39: 83-92.

Hamilton W J, Tilson R L, Frank L G. 1986. Sexual monomorphism in spotted hyenas, Crocuta crocuta. Ethology 71(1):63-73.

Henschel J R, Skinner J D. 1987. Social relationships and dispersal patterns in a clan of spotted hyaenas Crocuta crocuta in the Kruger National Park. South African Journal of Zoology 22:18-23.

Henschel J R, Skinner J D. 1991. Territorial behaviour by a clan of spotted hyaenas Crocuta crocuta. Ethology 88:223-235.

Hofer H, East M. 1993a. The commuting system of Serengeti spotted hyaenas: how a predator copes with migratory prey. I. Social organization. Animal Behaviour 46:547-557.

Hofer H, East M. 1993b. The commuting system of Serengeti spotted hyaenas: how a predator copes with migratory prey. II. Intrusion pressure and commuters' space use. Animal Behaviour 46:559-574.

Hofer H, East M. 1993c. The commuting system of Serengeti spotted hyaenas: how a predator copes with migratory prey. III. Attendance and maternal care. Animal Behaviour 46:575-589.

Hofer H, East M. 1995. Population dynamics, population size, and the commuting system of Serengeti spotted hyenas. Pages 332-363 in Serengeti II: Dynamics, Management, and Conservation of an Ecosystem, edited by A R E Sinclair and P Arcese. Chicago: University of Chicago Press.

Hofer H, East M L. 1997. Skewed offspring sex ratios and sex composition of twin litters in Serengeti 
spotted hyaenas (Crocuta crocuta) are a consequence of siblicide. Applied Animal Behavior Science 51:307-316.

Holekamp K E, Boydston E E, Szykman M, Graham I, Nutt K J, Birch S, Piskiel A, Singh M. 1999. Vocal recognition in the spotted hyaena and its possible implications regarding the evolution of intelligence. Animal Behaviour 80:383-395.

Holekamp K E, Ogutu J O, Dublin H T, Frank L G, Smale L. 1993. Fission of a spotted hyena clan: consequences of prolonged female absenteeism and causes of female emigration. Ethology 93:285-299.

Holekamp K E, Smale L. 1995. Rapid change in offspring sex ratios after clan fission in the spotted hyena. American Naturalist 145:261-278.

Holekamp K E, Smale L. 1998. Behavioral development in the spotted hyena. BioScience 48:997-1005.

Holekamp K E, Smale L, Szykman M. 1996. Rank and reproduction in the female spotted hyena. Journal of Reproduction and Fertility 108:229-237.

James W H, Hofer H. 1999. A note on sex ratios and sex combinations in Serengeti spotted hyaenas: siblicide and sub-binomial variance. Applied Animal Behaviour Science 65:153-158.

Joubert D, Joubert B. 1992. Eternal Enemies. Botswana: Wildlife Films.

Kruuk H. 1972. The Spotted Hyena: A Study of Predation and Social Behavior. Chicago: University of Chicago Press.

Langmore N E, Bennett A T D. 1999. Strategic concealment of sexual identity in an estrildid finch. Proceedings of the Royal Society of London B 266:543550.

Licht P, Frank L G, Pavgi S, Yalcinkaya T M, Siiteri P K, Glickman S E. 1992. Hormonal correlates of "masculinization" in the female spotted hyaena (Crocuta crocuta). II. Maternal and fetal steroids. Journal of Reproduction and Fertility 95:463-474

Licht P, Hayes T, Tsai P, Cunha G, Kim H, Golbus M, Hayward S, Martin M C, Jaffe R B, Glickman S E. 1998. Androgens and masculinization of genitalia in the spotted hyena (Crocuta crocuta). 1. Urogenital morphology and placental androgen production during fetal life. Journal of Reproduction and Fertility 113:105-116.

Lindeque M, Skinner J D. 1982. Fetal androgens and sexual mimicry in spotted hyaenas (Crocuta crocuta). Journal of Reproduction and Fertility 65:405410.

Matthews L H. 1939. Reproduction of the spotted hyaena (Crocuta crocuta Erxleben). Philosophical Transactions Series B 230:1-78.

Milgrom E. 1990. Steroid hormones. Pages 385-437 in Hormones: From Molecules to Disease, edited by E-E Baulieu and P A Kelly. New York: Chapman and Hall.

Mills M G L. 1990. Kalahari Hyaenas: Comparative Be- havioural Ecology of Two Species. London: Unwin Hyman.

Monaghan E P, Glickman S E. 1992. Hormones and aggressive behavior. Pages 261-285 in Behavioral Endrocrinology, edited by J B Becker et al. Cambridge (MA): MIT Press.

Norman M D, Finn J, Tregenza T. 1999. Female impersonation as an alternative reproductive strategy in giant cuttlefish. Proceedings of the Royal Society of London B 266:1347-1349.

Owens D, Owens M. 1996. Social dominance and reproductive patterns in brown hyaenas, Hyaena brunnea, of the central Kalahari desert. Animal Behaviour 51:535-551.

Owens M J, Owens D D. 1978. Feeding ecology and its influence on social organization in brown hyenas (Hyaena brunnae, Thunberg) of the Central Kalahari Desert. East African Wildlife Journal 16:113135.

Racey P A, Skinner J D. 1979. Endocrine aspects of sexual mimicry in spotted hyaenas Crocuta crocuta. Journal of Zoology 187:315-326.

Renfree M B, Short R V. 1988. Sex determination in marsupials: evidence for a marsupial-eutharian dichotomy. Philosophical Transactions of the Royal Society of London B 322:41-53.

Robertson H M. 1985. Female dimorphism and mating behaviour in a damselfly, Ischnura ramburi: females mimicking males. Animal Behaviour 33:805809.

Rohwer S, Fretwell S D, Niles D M. 1980. Delayed maturation in passerine plumages and the deceptive acquisition of resources. American Naturalist 115:400-437.

Saetre G-P, Slagsvold S. 1996. The significance of female mimicry in male contests. American Naturalist 147:981-995.

Shapiro D Y, Reeve H K, Pfennig D W. 1997. Recognition systems. Pages 69-96 in Behavioural Ecology: An Evolutionary Approach, edited by J R Krebs and N B Davies. Oxford: Blackwell Scientific Publications.

Shine R, Lemaster M P, Moore I T, Mason R T. 2000. The transvestite serpent: why do male garter snakes court (some) other males? Animal Behaviour 59:349-359.

Silk J B. 1983. Local resource competition and facultative adjustment of sex ratios in relation to competitive abilities. American Naturalist 121:56-66.

Sirot L K, Brockmann H J. 2001. Costs of sexual interactions to females in Rambur's forktail damselfly, Ischnura ramburi (Zygoptera: Coenagrionidae). Animal Behaviour 61:415-424.

Smale L, Frank L G, Holekamp K E. 1993. Ontogeny of dominance in free-living spotted hyaenas: juvenile rank relations with adult females and immigrant males. Animal Behaviour 46:467-477. 
Smale L, Holekamp K E, White P A. 1999. Siblicide revisited in the spotted hyaena: does it conform to obligate or facultative models? Animal Behaviour 58:545-551.

Smuts B B, Watanabe J M. 1990. Social relationships and ritualized greetings in adult male baboons ( $P a$ pio cynocephalus anubis). International Journal of Primatology 11:147-172.

Tilson R L, Hamilton W J. 1984. Social dominance and feeding patterns of spotted hyaenas. Animal Behaviour 32:715-724.

Trail P. 1990. Why should lek-breeders be monomorphic? Evolution 44:1837-1852.

Trivers R L. 1976. Sexual selection and resource-accruing abilities in Anolis garmani. Evolution 30:253-269.

van Jaarsveld A S, Skinner J D. 1991. Plasma androgens in spotted hyaenas (Crocuta crocuta): influence of social and reproductive development. Journal of Reproduction and Fertility 93:195-201.

Whateley A. 1980. Comparative body measurements of male and female spotted hyaenas from Natal. The Lammergeyer 28:40-43.

Wickler W. 1969. The Sexual Code. London: Weidenfeld \& Nicolson.

Wilson J D, George F W, Griffin J E. 1981. The hormonal control of sexual development. Science 211:1278-1284.

Wrangham R W, Peterson D. 1996. Demonic Males: Apes and the Origins of Human Violence. Boston: Houghton Mifflin.

Yalcinkaya T M, Siiteri P K, Vigne J-L, Licht P, Pavgi S, Frank L G, Glickman S E. 1993. A mechanism for virilization of female spotted hyenas in utero. Science 260:1929-1931. 